\title{
Optimal perioperative management of arterial blood pressure
}

\author{
This article was published in the following Dove Press journal: \\ Integrated Blood Pressure Control \\ 12 September 2014 \\ Number of times this article has been viewed
}

\author{
Laurent Lonjaret' \\ Olivier Lairez ${ }^{2}$ \\ Vincent Minville ${ }^{3}$ \\ Thomas Geeraerts ${ }^{3}$ \\ 'Department of Anesthesiology \\ and Intensive Care, Clinique des \\ eaux claires, Baie-Mahault, France; \\ ${ }^{2}$ Department of Cardiology, \\ ${ }^{3}$ Department of Anesthesiology and \\ Intensive Care, University Hospital of \\ Toulouse, University Toulouse \\ III - Paul Sabatier, Toulouse, France
}

\begin{abstract}
Perioperative blood pressure management is a key factor of patient care for anesthetists, as perioperative hemodynamic instability is associated with cardiovascular complications. Hypertension is an independent predictive factor of cardiac adverse events in noncardiac surgery. Intraoperative hypotension is one of the most encountered factors associated with death related to anesthesia. In the preoperative setting, the majority of antihypertensive medications should be continued until surgery. Only renin-angiotensin system antagonists may be stopped. Hypertension, especially in the case of mild to moderate hypertension, is not a cause for delaying surgery. During the intraoperative period, anesthesia leads to hypotension. Hypotension episodes should be promptly treated by intravenous vasopressors, and according to their etiology. In the postoperative setting, hypertension predominates. Continuation of antihypertensive medications and postoperative care may be insufficient. In these cases, intravenous antihypertensive treatments are used to control blood pressure elevation.
\end{abstract}

Keywords: hypertension, hypotension, perioperative, blood pressure control

\section{Introduction}

During anesthesia, maintenance of adequate tissue perfusion is mandatory. Unfortunately, tissue perfusion cannot be assessed easily. Cardiac output measurement and pulmonary artery occlusion pressure are useful guides to anesthesia, but in current practice, blood pressure and heart rate are used as the main hemodynamic targets. Perioperative blood pressure management is a key factor for anesthetists, as its instability is associated with adverse events. Preoperative hypertension is frequently encountered. Maintaining or halting antihypertensive medications should be discussed. During surgery, anesthesia may be associated with hypotension, whereas after surgery, hypertension predominates. Rapid, safe, and effective treatments should then be introduced. Optimal management of arterial blood pressure is clearly required in the perioperative setting to avoid complications.

\section{General considerations}

Perioperative hypertension occurs in $25 \%$ of hypertensive patients who undergo surgery. ${ }^{1}$ Nevertheless, there is a lack of consensus concerning treatment thresholds and appropriate therapeutic targets. ${ }^{1}$ During surgery, Reich et $\mathrm{al}^{2}$ proposed a value of systolic arterial pressure (SAP) $>160 \mathrm{mmHg}$ to define hypertension. ${ }^{2}$ Postoperative hypertension has been arbitrarily defined as SAP $\geq 190 \mathrm{mmHg}$ and/or diastolic arterial pressure $(\mathrm{DAP})>100 \mathrm{mmHg}$ on two consecutive readings after surgery. ${ }^{3}$ In current practice, during the perioperative period, $\mathrm{SAP} \geq 180 \mathrm{mmHg}$ and/or DAP $\geq 120 \mathrm{mmHg}$
Correspondence: Laurent Lonjaret Clinique des Eaux Claires, Moudong sud, 97 I 22 Baie Mahault, France

Tel +33645401752

Fax +33561777743

Email laurent.lonjaret@laposte.net 
is often considered significant and should be considered as hypertensive urgency. ${ }^{4}$

There is no widely accepted definition of intraoperative hypotension, resulting in different incidences being reported across studies. Many measurements could be analyzed, such as a decrease in SAP or mean arterial pressure (MAP) under a threshold, variation from baseline, combination of parameters, duration of hypotension, and administration of fluids or vasopressors. ${ }^{5}$ Bijker et al found that intraoperative hypotension occurs with anesthesia administration in 5\%-99\% of patients, in accordance with the definition used. ${ }^{5}$ For cesarean delivery under spinal anesthesia, the incidence of hypotension varies between $7.4 \%$ and $74.1 \%$ in accordance with various definitions of hypotension. ${ }^{6}$ Thus, even if hypotension is associated with adverse outcomes, the threshold and duration of hypotensive episodes leading to complications are not clearly defined. A decrease of SAP higher than $20 \%$ is often chosen to define perioperative hypotension.

\section{Blood pressure measurement}

Blood pressure may be measured using invasive or noninvasive methods. Invasive intra-arterial catheters may detect acute changes in blood pressure better than oscillometric measurements, and remain the method of choice when continuous monitoring is required.

Moreover, the site of measurement can induce significant variations in blood pressure readings. In a hypotensive setting, during aortic endografting, the femoral MAP is more accurate in predicting the value of the aortic MAP than the radial MAP. ${ }^{7}$ Noninvasive blood pressure is classically measured at the arm. It is important to know there is a poor agreement between mean blood pressure at the arm, ankle, and calf: MAP is higher when measured at the calf and ankle ( 4 and $8 \mathrm{mmHg}$, respectively) compared with the arm. ${ }^{8}$

\section{Risks associated with perioperative hypertension and hypotension}

Hypertension affects $26.4 \%$ of the global population. ${ }^{9}$ It is an independent predictive factor of cardiac adverse events in noncardiac surgery. ${ }^{10}$ In patients with known coronary artery disease or at high risk for coronary artery disease who are undergoing noncardiac surgery, preoperative hypertension increases risk for death by 3.8 times. ${ }^{11}$ Perioperative hypertension increases blood loss, myocardial ischemia, and cerebrovascular events. Isolated systolic hypertension is also associated with a $40 \%$ increase in the likelihood of perioperative cardiovascular morbidity in coronary artery surgery patients. ${ }^{12}$

Perioperative hemodynamic instability is associated with cardiovascular complications. Interestingly, multiple studies suggest that perioperative cardiac complications are associated with intraoperative hemodynamic instability, rather than acute intraoperative hypertension alone. A decrease of $40 \%$ in MAP and an episode of a MAP $<50 \mathrm{mmHg}$ during surgery are associated with cardiac events in high-risk patients. ${ }^{10}$ Even short episodes of intraoperative MAP of $<55 \mathrm{mmHg}$ are associated with acute kidney injury and myocardial injury after a noncardiac surgery. ${ }^{13}$ The threshold and duration at which an association might be found between a perioperative stroke and hypotension are not completely known. ${ }^{14}$ Intraoperative hypotension is one of the most encountered factors associated with death related to anesthesia. ${ }^{15}$

Optimal perioperative blood pressure management appears to be a key factor of patient care. Many factors influence perioperative blood pressure, such as factors linked to the patient (age, cardiovascular status, and antihypertensive treatment) and factors linked to the surgery (type of surgery, type of anesthesia, and perioperative position).

\section{Preoperative blood pressure control}

In current practice, a patient with hypertension may already have developed complications, which must be detected before surgery.

The first objective of preoperative evaluation is to know whether hypertension is controlled with medications or not. However, delaying surgery only for the purpose of blood pressure control may not be necessary, ${ }^{16}$ with the exception of stage 3 (SAP $>180 \mathrm{mmHg}$ and/or DAP $>110 \mathrm{mmHg}$ ) hypertension or in patients with target-organ damage. ${ }^{17}$ Delaying surgery is not strictly recommended, ${ }^{18}$ as rapidly acting agents can be used to control blood pressure and avoid an unnecessary surgery postponement. ${ }^{19}$

Cardiac evaluation before noncardiac surgery is based on active clinical conditions, functional capacity, known cardiovascular diseases and cardiac risk factors, risk, and urgency of surgery. ${ }^{18}$ Physical examination, routine laboratory tests, and/or noninvasive tests may be done. Systematic assessment of left ventricular function is not recommended in asymptomatic patients. ${ }^{18}$ Antihypertensive medications should be continued in the majority of cases (Table 1).

\section{Beta-blocker agents}

During the $1990 \mathrm{~s}$, promising studies showed the benefit of using perioperative beta-blockers. In the study by 
Table I Preoperative antihypertensive medications management

\begin{tabular}{ll}
\hline Medication & Management \\
\hline Beta blockers & Maintained until surgery \\
Calcium channel blockers & Maintained until surgery \\
$\begin{array}{l}\text { Renin-angiotensin } \\
\text { system inhibitors }\end{array}$ & Stopped the morning of surgery \\
Diuretics & Maintained until surgery (may be stopped \\
& the day of surgery in case of hypovolemia)
\end{tabular}

Mangano et al, ${ }^{20}$ adding atenolol in the perioperative period in patients at risk for coronary artery disease undergoing noncardiac surgery showed a reduction of mortality and cardiovascular complications for a period of 2 years after surgery. ${ }^{20}$ Poldermans et $\mathrm{al}^{21}$ found that bisoprolol reduces the incidence of death and nonfatal myocardial infarction in high-risk patients undergoing major vascular surgery. ${ }^{21}$ In contrast, the Perioperative Ischemic Evaluation (POISE) trial did not find any benefits of beta-blocker use in the perioperative period. In the POISE trial, patients were randomized to receive metoprolol, starting before surgery for a 30 day period, or placebo. The POISE study group found a decrease of myocardial infarction in the metoprolol group but a higher rate of deaths and strokes. ${ }^{22}$ In a retrospective study, Lindenauer et $\mathrm{a}^{23}$ found a positive effect of perioperative beta-blocker therapy only in high-risk patients undergoing noncardiac surgery, whereas low-risk patients had no benefit or possible harm..$^{23}$ These results led to a revision of practice guidelines in 2009. Beta-blocker medical therapy should be continued in patients who are receiving beta-blockers for treatment of conditions with American College of Cardiology Foundation/American Heart Association class 1 guideline indications, but routine administration of high-dose betablockers in the absence of dose titration is not useful and may be harmful to patients not currently taking beta-blockers who are undergoing noncardiac surgery. ${ }^{24}$

\section{Calcium channel blockers}

Calcium channel blockers are usually well tolerated in the perioperative setting. ${ }^{25}$ Calcium antagonists do not result in an exaggerated hypotensive response after induction of anesthesia. ${ }^{17}$ They may be continued safely right up to the morning of surgery, but administered with caution in the perioperative period in patients with impaired ventricular function and/or hypovolemia. ${ }^{26}$

\section{Renin-angiotensin system antagonists}

Interactions between angiotensin-converting enzyme inhibitors (ACEIs) or angiotensin II receptor antagonists (ARAs) and anesthesia are controversial. ACEIs or ARAs may increase the incidence of refractory hypotension during general anesthesia, limiting the response to ephedrine or phenylephrine. ${ }^{27}$ In this study, few patients were treated with ARAs ( $\mathrm{n}=12)$, but all developed a hypotension episode and four required the use of vasopressin.

Nevertheless, patients treated with ACEIs presented with hypotension in $67 \%$ of cases, without statistical significance, in comparison with patients treated with beta-blockers or calcium channel blockers (60\%). In a recent animal study, aging rats treated with captopril showed a lower MAP than untreated rats after propofol exposure. ${ }^{28}$ This study suggests that propofol vasodilatation is enhanced by ACEI use, through a non-NO-dependent pathway, in contrast to the classical vascular response to propofol. In hypertensive patients chronically treated with ACEIs, maintenance of therapy until the day of surgery may increase the probability of hypotension at induction. ${ }^{29}$ Nevertheless, this study may have some limitations.

Coriat et $\mathrm{al}^{29}$ studied first-generation ACEIs. They compared the incidence of hypotension at induction of anesthesia when ACEIs were stopped (12 hours before surgery for enalapril and 24 hours before surgery for captopril) or continued until surgery. Moreover, the daily dose of antihypertensive medication was lower (nonstatistically significant) in the withdrawn groups. Discontinuation of ACEI or ARA therapy at least 10 hours before anesthesia is associated with a reduced risk for immediate postinduction hypotension. ${ }^{30} \mathrm{In}$ their retrospective study, Comfere et $a l^{30}$ found a reduction of moderate hypotension defined by a SAP $\leq 85 \mathrm{mmHg}$, but not of severe hypotension, defined by a $\mathrm{SAP} \geq 65 \mathrm{mmHg}$. Anesthetic management was nonstandardized, which could have induced variability between the groups. In addition, most hypotensive episodes prompted relatively simple interventions (fluids, ephedrine, or phenylephrine). Interestingly, higher doses (non-statistically significant) of ephedrine and phenylephrine were used for patients who took their last ACEI/ARA 10 hours or more before induction. Withholding ACEIs and ARAs the morning of surgery has been proposed by international guidelines. ${ }^{18}$ Nevertheless, in a review, Sear suggests continuing antihypertensive therapies up to the morning of surgery, especially for ambulatory surgery. ${ }^{17}$

In a study performed by Sear et al, ${ }^{31}$ no differences were found in hypotension episodes after the induction of anesthesia, between the four drugs used in monotherapy (ACEIs, beta-blockers, calcium channel blockers, and diuretics). ${ }^{31}$ Reich et al ${ }^{32}$ did not find any association between ACEIs and hypotension, arguing 
that the ASA physical status $\geq 3$ is probably a stronger predictor of perioperative hypotension than preoperative antihypertensive drugs by themselves. ${ }^{32}$ ACEI treatment does not further aggravate the blood pressure decrease under total intravenous anesthesia for minor surgery. ${ }^{33}$

Little is known about the interaction between ACEIs or ARAs and spinal anesthesia. Höhne et $\mathrm{al}^{34}$ found that longterm ACEI treatment does not further exaggerate the blood pressure decrease in the early phase of spinal anesthesia. ${ }^{34}$

\section{Diuretics}

Diuretics should not be stopped before surgery but should be used with caution in the perioperative setting, as they may be associated with hypovolemia and hypokalemia for loop diuretics. In patients undergoing carotid endarterectomy under general anesthesia, preoperative diuretic therapy is associated with an increased vasopressor requirement to maintain blood pressure when used as a single antihypertensive or as a part of a multiple-antihypertensive regimen. ${ }^{35}$

\section{Association of hypertensive medications}

Patients taking several antihypertensive therapies are more exposed to intraoperative hypotension. Diuretic therapy associated with ACEIs or ARAs increase the rate of hypotension in patients undergoing noncardiac surgery. ${ }^{36}$ Patients taking three or more antihypertensive agents require more vasopressors during general anesthesia. ${ }^{35}$

\section{Perioperative blood pressure control \\ Effects of general anesthesia on blood pressure}

General anesthesia

A hypertensive response is associated with laryngoscopy and tracheal intubation because of a catecholamine release. ${ }^{37}$ In current practice, a moderate increase of blood pressure may be observed just after laryngoscopy, especially when no opioid drugs are used for the induction of anesthesia. $^{38}$

Hypotension is frequent between the induction of anesthesia and the beginning of surgery. In their study, Reich et al showed that hypotension was more frequent during the 5-10 minute postinduction period compared with the 0-5 minute period. ${ }^{32}$ Hypotension was defined as either MAP decrease of more than $40 \%$ and MAP $<70 \mathrm{mmHg}$, or MAP $<60 \mathrm{mmHg}$ alone. Its incidence is estimated at 7.7\% in American Society of Anesthesiologist (ASA) I-II status patients and $12.6 \%$ in ASA III-V patients. Multivariate predictors of hypotension after anesthetic induction included: ASA physical status III-V, baseline MAP $<70$ $\mathrm{mmHg}$, age $\geq 50$ years, increasing dosage of fentanyl and use of propofol at induction.

\section{Intravenous agents}

In their retrospective study, Hug et $\mathrm{al}^{39}$ found that after propofol induction, $15.7 \%$ of patients had a SAP $<90 \mathrm{mmHg}$, and $77 \%$ of these episodes occurred in the first 10 minutes. ${ }^{39}$ Propofol, used alone at induction of anesthesia, promotes a significant decrease in arterial blood pressure compared with thiopentone or etomidate. ${ }^{32,38}$ Even with reduced doses, propofol is a more hypotensive agent than etomidate. ${ }^{40}$ Propofol-induced hypotension is mediated by an inhibition of the sympathetic nervous system and impairment of baroreflex regulatory mechanisms. ${ }^{41}$ Moreover, propofol has a direct effect on vessels: it causes a dose-related decrease of potassium-induced tone in veins at low dose and arterioles at higher dose. ${ }^{42}$

Etomidate preserves hemodynamic stability through maintenance of both sympathetic outflow and autonomic reflexes. ${ }^{41}$ In patients with severe aortic stenosis, etomidate induces less hypotension than propofol after the induction of anesthesia. ${ }^{43}$

\section{Volatile anesthetic agents}

Volatile anesthetics may be used for induction and/or for maintenance of anesthesia. They are associated with a myocardial protective effect and improve postischemic recovery at a cellular level in isolated hearts, in animals, and in humans. In patients undergoing cardiac surgery, desflurane and sevoflurane decrease morbidity and mortality in comparison with a total intravenous anesthesia regimen. ${ }^{44}$ It can also be beneficial to use volatile anesthetic agents during noncardiac surgery for the maintenance of general anesthesia in hemodynamically stable patients at risk for myocardial ischemia. ${ }^{18}$

Induction with sevoflurane is associated with better blood pressure maintenance than with propofol, but more patients found this technique unpleasant. ${ }^{45}$ Volatile anesthetic agents have effects on blood pressure, depending on their concentration. Increasing concentrations of volatile anesthetics decrease blood pressure. ${ }^{46}$

\section{Xenon}

Xenon is able to exert anesthetic properties with a remarkable hemodynamic stability in healthy patients undergoing elective surgery. ${ }^{47}$ Xenon induces general anesthesia without impairment of cardiac output and vascular resistance by increasing norepinephrine plasma concentration. ${ }^{48}$ In vitro, xenon inhibits norepinephrine transporter and reduces the uptake of norepinephrine in neuronal cells. In patients with 
known coronary artery disease undergoing noncardiac surgery, xenon-remifentanil anesthesia provides a higher arterial pressure and an improved left ventricular function (Tei index) than propofol-remifentanil anesthesia. ${ }^{49}$

\section{Effects of spinal anesthesia on blood pressure}

Spinal anesthesia provides a sympathectomy-induced hypotension. A decrease in systemic vascular resistance is observed, leading to an acute drop in venous return. Hypotension is the most encountered complication after spinal anesthesia. ${ }^{50}$ In their study, Carpenter et $\mathrm{a}^{51}$ found that hypotension developed in one-third of patients after spinal anesthesia and that the factors associated with hypotension were age, level of spinal puncture, baseline blood pressure, peak block height, combination with general anesthesia, and addition of phenylephrine to the local anesthetic. ${ }^{51}$ The height of the sympathetic blockade is determined by the cephalad distribution of the local anesthetic in the cerebrospinal fluid. The amount of local anesthetics administered strongly influences this blockage, and therefore the blood pressure drop. ${ }^{52,53}$ Many factors have been expected to influence the sensory block level: local anesthetics baricity, volume (local anesthetics concentration), and patient position during spinal anesthesia. In their study, Malinovsky et al ${ }^{54}$ tested six different preparations of $10 \mathrm{mg}$ bupivacaine (from $2-10 \mathrm{~mL}$ isobaric or hyperbaric bupivacaine) and found that volume had no significant influence on either cephalad spread for either isobaric or hyperbaric bupivacaine. A greater maximal cephalad spread of anesthesia was obtained with diluted isobaric bupivacaine, but hypotensive episodes were more frequent with a low volume of isobaric bupivacaine. Malinovsky et al hypothesize that decreasing the local anesthetic concentration limited the concentration of local anesthetics penetrating the nerve. ${ }^{54}$ The effect of the patient's position during spinal anesthesia has been well evaluated in obstetrics. Hypotension occurs less frequently when spinal anesthesia for a cesarean section is performed in the lateral position compared with the sitting position. ${ }^{55} \mathrm{In}$ contrast, after the spinal injection of the local anesthetic in patients undergoing cesarean section, maintenance in the sitting position for 5 minutes results in lower sensory block levels and ephedrine requirements for hyperbaric bupivacaine. ${ }^{56}$

\section{Other factors influencing perioperative blood pressure} Volemia

Volemia is a key factor for blood pressure variations. Hypovolemia resulting from blood loss or dehydration is a frequent cause of hypotension in the perioperative setting.

\section{Perioperative position and surgical technique}

The upright sitting or beach chair position is associated with a higher incidence of hypotension and risk for cerebral ischemia. During shoulder surgery in the beach chair position, intraoperative hypotension is increased by preoperative use of antihypertensive medication. ${ }^{57}$ Prone positioning decreases venous return (inferior vena cava compression) and left ventricular compliance (increase of intrathoracic pressure), resulting in a decrease in the cardiac index, but MAP is maintained at baseline levels because of an increase of systemic vascular resistance. ${ }^{58}$

During laparoscopic cholecystectomy in nonobese patients, MAP decreases after induction of anesthesia and tilting to the head-up position but increases after peritoneal insufflation. ${ }^{59}$ In obese patients, surgical pneumoperitoneum results in the deterioration of cardiac output without affecting MAP. ${ }^{60}$ During robot-assisted laparoscopic radical prostatectomy in $45^{\circ}$ Trendelenburg position, pneumoperitoneum increases MAP by $25 \%$, but addition of Trendelenburg position does not modify MAP levels. ${ }^{61}$

Tourniquet inflation causes hemodynamic changes. In young men undergoing knee surgery under general anesthesia, MAP increases $26 \%$ during inflation and returns to basal values after deflation. ${ }^{62}$ Aortic cross-clamping induces an increase in blood pressure, whereas unclamping leads to hypotension. ${ }^{63}$

\section{Mechanical ventilation}

Mechanical ventilation, especially positive end-expiratory pressure, decreases the blood volume in the intrathoracic vascular bed and heart, and decreases cardiac filling and cardiac output via the Franck-Starling relationship. ${ }^{64,65}$ In fact, mechanical ventilation decreases right ventricular preload (venous return), and increases right ventricular afterload (pulmonary vascular resistance) and left ventricular afterload. These effects may lead to hypotension.

\section{Anaphylaxis and sepsis}

Anaphylaxis must be evoked when acute hypotension remains unexplained ${ }^{66}$ In patients with severe sepsis, perioperative resuscitation using fluids, vasopressors, and inotropes, as well as antimicrobial therapy, is fundamental. ${ }^{67}$

\section{How to avoid perioperative hypotension Titrated general anesthesia}

To limit the hypotension induced by intravenous drugs, anesthesia may be titrated to clinical response, especially in the elderly or in septic patients. In patients with severe sepsis, the choice of the induction agent is less important 
than the care with which they are administered. ${ }^{67}$ To guide induction anesthesia, bispectral index (BIS) monitoring may be helpful. BIS monitoring identifies the depth of anesthesia. Deep hypnosis (BIS <45) has been associated with postoperative complications and mortality. Controlling the depth of anesthesia limits the hypotensive effect of anesthetic drugs. ${ }^{68}$ Moreover, patients may have different anesthetic sensitivity: low anesthetic concentration surprisingly may be associated with a low BIS and low MAP. ${ }^{69}$

\section{Low doses, unilateral and continuous spinal anesthesia}

Several methods have been proposed to reduce the incidence of spinal anesthesia-induced hypotension, especially using low doses of local anesthetics. To decrease local anesthetic dose, Ben-David et al have added opioid analgesics. ${ }^{53}$ Moreover, baricity of local anesthetics combined with the patient's position after spinal anesthesia have been used to prevent hypotension. Unilateral spinal anesthesia which is achieved by injecting a small dose of hyperbaric bupivacaine into the patients placed in the lateral position for 15 minutes, reduces the incidence of hypotension during spinal anesthesia. ${ }^{70}$ Unilateral spinal anesthesia also causes less hypotension than general anesthesia with sevoflurane. ${ }^{71}$ Finally, titration of local anesthetics decreases hypotension episodes. Continuous spinal anesthesia provides less hypotension than a single-shot technique. ${ }^{72}$ It allows incremental dosing of local anesthetics and can safely be used in patients with cardiac diseases. ${ }^{73}$ Continuous spinal anesthesia provides better blood pressure stability than general anesthesia (with propofol or sevoflurane) in elderly patients with hip fractures. ${ }^{74}$ Nevertheless, low doses of local anesthetics may compromise anesthetic efficacy. ${ }^{75}$ In fact, if the dose administered is insufficient, patients must also have a general anesthesia. ${ }^{76}$

\section{Hypotension treatment}

During anesthesia, blood pressure can be sustained by three vasopressor systems: the sympathetic nervous system, the renin-angiotensin system, and vasopressin. ${ }^{77}$ Keeping normovolemia is mandatory to avoid intraoperative hypotension (not considered in this review). Hypotension must be quickly treated by an intravenous agent and a decrease of depth of anesthesia to limit its duration (Figure 1).

\section{Etiology}

Intraoperative hypotension must be treated according to its cause, so it is critical to determine the pathophysiological process conducive to perioperative hypotension, such as:

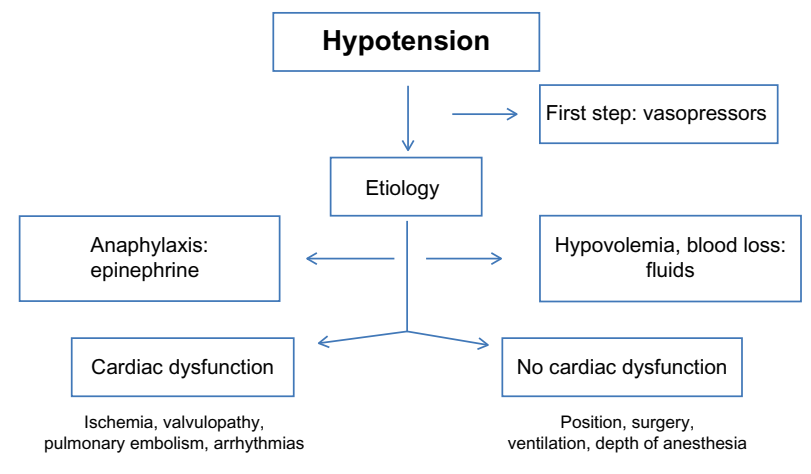

Figure I Perioperative hypotension management.

effect of anesthetic agents, hypovolemia, position or surgical technique, cardiac etiology, effect of mechanical ventilation, or anaphylaxis. Moreover, the severity of hypotension, associated signs, and the effect of initial therapy can be used to guide the treatment. After anesthesia induction, hypotension is mainly associated with vasoplegia (effect of anesthetic drugs) and the beginning of mechanical ventilation. During surgery, hypotension may be linked to hypovolemia, high doses of anesthetics, and heart failure. In patients undergoing cardiac surgery or with known cardiac diseases, cardiac dysfunction should be discussed. ${ }^{78}$ Short-acting vasopressors are used to restore blood pressure levels (Table 2).

\section{Ephedrine and phenylephrine}

Ephedrine is the first-line treatment of intraoperative hypotension during general anesthesia. Ephedrine is an indirect alpha and beta-adrenergic agonist, whereas phenylephrine is a direct alpha-agonist of the sympathetic system. These drugs have been well studied in the obstetrics setting. A doseresponse study of prophylactic infusions of phenylephrine and ephedrine in the prevention of hypotension after spinal anesthesia for cesarean delivery demonstrated a potency ratio of $81: 1 .^{79}$ Both ephedrine and phenylephrine are effective in

Table 2 Parenteral drugs for treatment of perioperative hypotension

\begin{tabular}{llll}
\hline Drug & Initial dose & $\begin{array}{l}\text { Onset of } \\
\text { action, } \\
\text { minutes }\end{array}$ & $\begin{array}{l}\text { Duration } \\
\text { of action, } \\
\text { minutes }\end{array}$ \\
\hline Ephedrine & $3-6 \mathrm{mg}$ & $\mathrm{I}-3$ & $15-20$ \\
Phenylephrine & $50-100 \mu \mathrm{g}$ & $\mathrm{I}-3$ & $10-20$ \\
Norepinephrine & $0.1-0.4 \mu \mathrm{g} / \mathrm{kg} /$ minute & Immediate & $5-15$ \\
Epinephrine & $(\mathrm{Cl})$ & Immediate & $5-15$ \\
Terlipressin & $0.1-1 \mathrm{mg}^{*}$ & 2 & $30-60$ \\
\hline
\end{tabular}

Notes: *In case of anaphylaxis (grade III-IV); "in case of refractory arterial hypotension (in patients with renin-angiotensin system inhibitors).

Abbreviation: $\mathrm{Cl}$, continuous infusion. 
the management of spinal anesthesia-induced hypotension, but phenylephrine is now the first choice in the obstetrics setting. ${ }^{80}$ Ephedrine increases heart rate, whereas phenylephrine decreases it. In consequence, ephedrine is a better drug to maintain cardiac output.

\section{Norepinephrine and epinephrine}

Norepinephrine is a direct alpha-1 adrenergic agonist, with a short duration of action. Norepinephrine is used in continuous infusion after the failure of first-line treatments (ephedrine, phenylephrine) to restore blood pressure to baseline levels. Moreover, norepinephrine is a good vasopressor agent choice in the treatment of patients with shock. ${ }^{81}$ Epinephrine is an alpha- and beta-adrenergic agonist. It remains the treatment of choice in cases of anaphylaxis during anesthesia. ${ }^{82}$

\section{Terlipressin}

Terlipressin, a long-acting synthetic analogue of vasopressin, stimulates vasopressin receptors and induces arterial constriction. Terlipressin is effective in rapidly correcting refractory hypotension in patients chronically treated with antagonists of the renin-angiotensin system without impairing left ventricular function. ${ }^{83}$ Terlipressin has been shown to be as effective as norepinephrine in correcting arterial hypotension after failure of ephedrine in patients under general anesthesia, with a shorter onset of action and a longer duration of action. ${ }^{84}$

\section{Perioperative hypertension}

Perioperative hypertension may occur during the induction of anesthesia, especially if no opioid analgesics are used. Helfman et al showed that lidocaine, fentanyl, and esmolol are efficient in controlling blood pressure during tracheal intubation. ${ }^{85}$ Moreover, during surgery, hypertension is mainly associated with acute pain-induced sympathetic stimulation. ${ }^{1}$ Specific surgical patterns (tourniquet, aortic cross-clamping) may also induce hypertension. In current practice, increasing the depth of anesthesia often corrects intraoperative hypertension.

If blood pressure is still uncontrolled after increasing the depth of anesthesia, a short-acting antihypertensive therapy may be used, such as in the postoperative setting.

\section{Postoperative blood pressure control \\ Postoperative hypertension} General considerations

In the postanesthesia care unit, during anesthesia awakening, many factors may promote hypertension, such as pain, anxiety, hypoxemia, hypercarbia, hypothermia and shivering, urinary retention, and hypervolemia. In the following days, hypertension may be associated with discontinuation of antihypertensive medication. ${ }^{86}$

The ideal agent for hypertension treatment should be rapid-acting, predictable and easily titrated, safe, inexpensive, and convenient. ${ }^{1}$ In Europe, in the setting of acute hypertension, patients are currently managed with a variety of agents, with those most commonly used being nitroglycerine, urapidil, and clonidine. ${ }^{87}$ Parenteral antihypertensive agents for treatment of perioperative hypertension are summarized in Table 3.

\section{Beta-blockers}

Esmolol is a short-acting cardioselective beta-blocker with a rapid onset ( 1 minute) and a short duration of action ( $<20$ minutes). A dose-response relationship between esmolol and hypotension has been observed. ${ }^{88}$ An initial low dose bolus followed by a continuous infusion limits severe hypotension episodes. ${ }^{88}$ Labetalol is a combined alpha and beta-blocker, with an onset of action of less than 5 minutes and duration of action of 2-4 hours. Labetalol is administered as a repeated intravenous bolus of $20 \mathrm{mg}$.

\section{Calcium channel blockers}

Clevidipine is an ultra-short-acting selective arteriolar vasodilator. Clevidipine has a short half-life and is typically administered as a continuous infusion. In the Evaluation of Clevidipine in the Perioperative Treatment of Hypertension Assessing Safety Events (ECLIPSE) trials, clevidipine has

Table 3 Parenteral antihypertensive agents for treatment of perioperative hypertension

\begin{tabular}{|c|c|c|c|}
\hline Agent & Initial dose & $\begin{array}{l}\text { Onset of } \\
\text { action }\end{array}$ & $\begin{array}{l}\text { Duration of } \\
\text { action }\end{array}$ \\
\hline Esmolol & $\begin{array}{l}250-500 \mu \mathrm{g} / \mathrm{kg} \\
\text { (followed by } 25-50 \mu \mathrm{g} / \\
\mathrm{kg} / \text { minute in } \mathrm{Cl} \text { ) }\end{array}$ & I minutes & $10-20$ minutes \\
\hline Labetalol & $20 \mathrm{mg}$ & $2-5$ minutes & 6 hours \\
\hline Clevidipine & $0.5 \mu \mathrm{g} / \mathrm{kg} /$ minute $(\mathrm{Cl})$ & $2-4$ minutes & 5-15 minutes \\
\hline Nicardipine & $\mathrm{I} \mathrm{mg}$ or $5 \mathrm{mg} / \mathrm{hour}(\mathrm{Cl})$ & $\begin{array}{l}2 \text { minutes, } \\
5-15 \text { minutes }\end{array}$ & $\begin{array}{l}\text { 2-4 hours, } \\
4-6 \text { hours }\end{array}$ \\
\hline Nitroprusside & $0.5 \mu \mathrm{g} / \mathrm{kg} /$ minute $(\mathrm{Cl})$ & Immediate & $\mathrm{I}-2$ minutes \\
\hline Nitroglycerin & $5 \mu \mathrm{g} / \min (\mathrm{Cl})$ & $2-5$ minutes & $3-5$ minutes \\
\hline Clonidine & $150 \mu \mathrm{g}$ & 30 minutes & 4-6 hours \\
\hline Urapidil & $25 \mathrm{mg}$ & 2 minutes & 4-5 hours \\
\hline Enalaprilat & $0.625-1.25 \mathrm{mg}$ & 15 minutes & 6 hours \\
\hline Fenoldopam & $0.1 \mu \mathrm{g} / \mathrm{kg} /$ minute $(\mathrm{Cl})$ & 5 minutes & $30-60$ minutes \\
\hline Hydralazine & $3-20 \mathrm{mg}$ & $5-15$ minutes & $6-12$ hours \\
\hline
\end{tabular}

Abbreviations: $\mathrm{Cl}$, continuous infusion; min, minute. 
been shown to be more effective than nitroglycerin and nitroprusside, and equivalent to nicardipine for maintaining blood pressure within the prespecified blood pressure range. ${ }^{89}$ Nicardipine is a short-acting dihydropyridine calcium channel blocker. Nicardipine is an easily titratable and potent vasodilator, which may be administered as an intravenous bolus or continuous infusion. Its onset of action is about 2 minutes for an intravenous bolus, with a duration of action of about 3 hours. Nicardipine has many of the properties of an ideal drug for the treatment of postoperative hypertension. ${ }^{90}$

\section{Nitroprusside and nitroglycerin}

Sodium nitroprusside is an arterial and venous vasodilator that decreases cardiac preload and afterload without inotropic or chronotropic effects. It has an immediate onset of action and a short duration of action (1-2 minutes). Nitroglycerin is a direct vasodilator (especially venodilator) with a rapid onset of action and a short duration. Nitroglycerin also dilates coronary arteries, but it has a limited efficacy and promotes a reflex tachycardia. ${ }^{91}$

\section{Alpha-2 agonists}

Perioperative use of alpha-2 agonists has been shown to maintain perioperative hemodynamic stability by reducing sympathetic activity, thereby preventing major cardiac complications. ${ }^{92,93}$ Nevertheless, with regard to adverse effects, alpha-2 adrenergic agonists significantly increase perioperative hypotension and bradycardia. ${ }^{92,93}$ Alpha-2 agonists may be considered for perioperative control of hypertension for patients with known coronary artery disease.$^{18}$ Clonidine may also be used in the postoperative setting to treat hypertension.

\section{Alpha-I-adrenergic antagonist}

Urapidil is a peripheral postsynaptic alpha 1-adrenoceptor antagonist with central agonistic action at serotonin 5-HT1A receptors. It reduces blood pressure by decreasing peripheral vascular resistance. It is effective in controlling various hypertensive crises and hypertension associated with pregnancy or surgery, and is similar to or better than other first-line agents used in these conditions. ${ }^{94}$ In the study by van der Stroom et al, urapidil was effective in lowering arterial blood pressure after coronary artery surgery, but one third of the patients treated with urapidil developed hypotension after 60 minutes of continuous infusion. ${ }^{95}$

\section{Postoperative hypotension}

Postoperative hypotension is often linked to hypovolemia, cardiac dysfunction, or prolonged infusion of anesthetic agents.

\section{Summary}

Perioperative blood pressure instability is associated with cardiac, renal, and neurologic adverse events. There is still no consensual definition for perioperative hypertension and hypotension. Anesthesia induces a decrease in blood pressure after induction, which is often resolved by sympathetic agonists. Antihypertensive medications should be continued until the day of surgery with the exception of renin-angiotensininterfering agents, which may be not be continued until the day of anesthesia

In contrast, in the postoperative period, hypertension predominates. Continuation of antihypertensive medications and the use of short-acting antihypertensive agents allows for effective blood pressure control.

\section{Disclosure}

The authors report no conflicts of interest in this work.

\section{References}

1. Varon J, Marik PE. Perioperative hypertension management. Vasc Health Risk Manag. 2008;4(3):615-627.

2. Reich DL, Bennett-Guerrero E, Bodian CA, Hossain S, Winfree W, Krol M. Intraoperative tachycardia and hypertension are independently associated with adverse outcome in noncardiac surgery of long duration. Anesth Analg. 2002;95(2):273-277.

3. Chobanian AV, Bakris GL, Black HR, et al; National High Blood Pressure Education Program Coordinating Committee. The Seventh Report of the Joint National Committee on Prevention, Detection, Evaluation, and Treatment of High Blood Pressure: the JNC 7 report. JAMA. 2003;289(19):2560-2572.

4. Desai RG, Muntazar M, Goldberg ME. Strategies for managing perioperative hypertension. Curr Hypertens Rep. 2009;11(3):173-177.

5. Bijker JB, van Klei WA, Kappen TH, van Wolfswinkel L, Moons KG, Kalkman CJ. Incidence of intraoperative hypotension as a function of the chosen definition: literature definitions applied to a retrospective cohort using automated data collection. Anesthesiology. 2007;107(2):213-220.

6. Klöhr S, Roth R, Hofmann T, Rossaint R, Heesen M. Definitions of hypotension after spinal anaesthesia for caesarean section: literature search and application to parturients. Acta Anaesthesiol Scand. 2010;54(8):909-921.

7. Ruiz S, Minville V, Asehnoune K, et al. Study of agreement of aortic, radial and femoral blood pressures during aortic endografting. Ann Fr Anesth Reanim. 2013;32(9):e97-e101.

8. Moore C, Dobson A, Kinagi M, Dillon B. Comparison of blood pressure measured at the arm, ankle and calf. Anaesthesia. 2008;63(12): 1327-1331.

9. Kearney PM, Whelton M, Reynolds K, Muntner P, Whelton PK, He J. Global burden of hypertension: analysis of worldwide data. Lancet. 2005;365(9455):217-223

10. Kheterpal S, O'Reilly M, Englesbe MJ, et al. Preoperative and intraoperative predictors of cardiac adverse events after general, vascular, and urological surgery. Anesthesiology. 2009;110(1):58-66.

11. Browner WS, Li J, Mangano DT; The Study of Perioperative Ischemia Research Group. In-hospital and long-term mortality in male veterans following noncardiac surgery. JAMA. 1992;268(2):228-232.

12. Aronson S, Boisvert D, Lapp W. Isolated systolic hypertension is associated with adverse outcomes from coronary artery bypass grafting surgery. Anesth Analg. 2002;94(5):1079-1084. 
13. Walsh M, Devereaux PJ, Garg AX, et al. Relationship between intraoperative mean arterial pressure and clinical outcomes after noncardiac surgery: toward an empirical definition of hypotension. Anesthesiology. 2013;119(3):507-515.

14. Bijker JB, Gelb AW. Review article: the role of hypotension in perioperative stroke. Can J Anaesth. 2013;60(2):159-167.

15. Lienhart A, Auroy Y, Péquignot F, et al. Survey of anesthesia-related mortality in France. Anesthesiology. 2006;105(6):1087-1097.

16. Hanada S, Kawakami H, Goto T, Morita S. Hypertension and anesthesia. Curr Opin Anaesthesiol. 2006;19(3):315-319.

17. Sear JW. Perioperative control of hypertension: when will it adversely affect perioperative outcome? Curr Hypertens Rep. 2008;10(6):480-487.

18. Fleisher LA, Beckman JA, Brown KA, et al; American College of Cardiology/American Heart Association Task Force on Practice Guidelines (Writing Committee to Revise the 2002 Guidelines on Perioperative Cardiovascular Evaluation for Noncardiac Surgery); American Society of Echocardiography; American Society of Nuclear Cardiology; Heart Rhythm Society; Society of Cardiovascular Anesthesiologists; Society for Cardiovascular Angiography and Interventions; Society for Vascular Medicine and Biology; Society for Vascular Surgery. ACC/AHA 2007 guidelines on perioperative cardiovascular evaluation and care for noncardiac surgery: executive summary: a report of the American College of Cardiology/American Heart Association Task Force on Practice Guidelines (Writing Committee to Revise the 2002 Guidelines on Perioperative Cardiovascular Evaluation for Noncardiac Surgery). Anesth Analg. 2008;106(3):685-712.

19. Weksler N, Klein M, Szendro G, et al. The dilemma of immediate preoperative hypertension: to treat and operate, or to postpone surgery? J Clin Anesth. 2003;15(3):179-183.

20. Mangano DT, Layug EL, Wallace A, Tateo I; Multicenter Study of Perioperative Ischemia Research Group. Effect of atenolol on mortality and cardiovascular morbidity after noncardiac surgery. $N$ Engl J Med 1996;335(23):1713-1720.

21. Poldermans D, Boersma E, Bax JJ, et al; Dutch Echocardiographic Cardiac Risk Evaluation Applying Stress Echocardiography Study Group. The effect of bisoprolol on perioperative mortality and myocardial infarction in high-risk patients undergoing vascular surgery. N Engl J Med. 1999;341(24):1789-1794.

22. POISE study group. Effects of extended-release metoprolol succinate in patients undergoing non-cardiac surgery (POISE trial): a randomized controlled trial. Lancet. 2008;31:1839-1847.

23. Lindenauer PK, Pekow P, Wang K, Mamidi DK, Gutierrez B, Benjamin EM. Perioperative beta-blocker therapy and mortality after major noncardiac surgery. N Engl J Med. 2005;353(4):349-361.

24. Fleischmann KE, Beckman JA, Buller CE, et al. 2009 ACCF/AHA focused update on perioperative beta blockade: a report of the American college of cardiology foundation/American heart association task force on practice guidelines. Circulation. 2009;120(21):2123-2151.

25. Durand PG, Lehot JJ, Foëx P. Calcium-channel blockers and anaesthesia. Can J Anaesth. 1991;38(1):75-89.

26. Reves JG, Kissin I, Lell WA, Tosone S. Calcium entry blockers: uses and implications for anesthesiologists. Anesthesiology. 1982;57(6) 504-518.

27. Brabant SM, Bertrand M, Eyraud D, Darmon PL, Coriat P. The hemodynamic effects of anesthetic induction in vascular surgical patients chronically treated with angiotensin II receptor antagonists. Anesth Analg. 1999;89(6):1388-1392.

28. Gragasin FS, Bourque SL, Davidge ST. Propofol increases vascular relaxation in aging rats chronically treated with the angiotensinconverting enzyme inhibitor captopril. Anesth Analg. 2013;116(4): 775-783.

29. Coriat P, Richer C, Douraki T, et al. Influence of chronic angiotensinconverting enzyme inhibition on anesthetic induction. Anesthesiology. 1994;81(2):299-307.

30. Comfere T, Sprung J, Kumar MM, et al. Angiotensin system inhibitors in a general surgical population. Anesth Analg. 2005;100(3):636-644.
31. Sear JW, Jewkes C, Tellez JC, Foëx P. Does the choice of antihypertensive therapy influence haemodynamic responses to induction, laryngoscopy and intubation? Br J Anaesth. 1994;73(3):303-308.

32. Reich DL, Hossain S, Krol M, et al. Predictors of hypotension after induction of general anesthesia. Anesth Analg. 2005;101(3):622-628.

33. Schulte E, Ziegler D, Philippi-Höhne C, Kaczmarcyk, Boemke W. Angiotensin-converting enzyme inhibition and blood pressure response during total intravenous anesthesia for minor surgery. Acta Anaesthesiol Scand. 2011;55(4):435-443.

34. Höhne C, Meier L, Boemke W, Kaczmarczyk G. ACE inhibition does not exaggerate the blood pressure decrease in the early phase of spinal anaesthesia. Acta Anaesthesiol Scand. 2003;47(7):891-896.

35. Anastasian ZH, Gaudet JG, Connolly ES Jr, Arunajadai S, Heyer EJ. The effect of antihypertensive class on intraoperative pressor requirements during carotid endarterectomy. Anesth Analg. 2011;112(6):1452-1460.

36. Kheterpal S, Khodaparast O, Shanks A, O'Reilly M, Tremper KK. Chronic angiotensin-converting enzyme inhibitor or angiotensin receptor blocker therapy combined with diuretic therapy is associated with increased episodes of hypotension in noncardiac surgery. J Cardiothorac Vasc Anesth. 2008;22(2):180-186.

37. Brossy MJ, James MF, Janicki PK. Haemodynamic and catecholamine changes after induction of anaesthesia with either thiopentone or propofol with suxamethonium. Br J Anaesth. 1994;72(5): 596-598.

38. Harris CE, Murray AM, Anderson JM, Grounds RM, Morgan M. Effects of thiopentone, etomidate and propofol on the haemodynamic response to tracheal intubation. Anaesthesia. 1988;43(s1)(Suppl):32-36.

39. Hug CC Jr, McLeskey CH, Nahrwold ML, et al. Hemodynamic effects of propofol: data from over 25,000 patients. Anesth Analg. 1993; 77(4)(Suppl):S21-S29.

40. Möller Petrun A, Kamenik M. Bispectral index-guided induction of general anaesthesia in patients undergoing major abdominal surgery using propofol or etomidate: a double-blind, randomized, clinical trial. Br J Anaesth. 2013;110(3):388-396.

41. Ebert TJ, Muzi M, Berens R, Goff D, Kampine JP. Sympathetic responses to induction of anesthesia in humans with propofol or etomidate. Anesthesiology. 1992;76(5):725-733.

42. Bentley GN, Gent JP, Goodchild CS. Vascular effects of propofol: smooth muscle relaxation in isolated veins and arteries. J Pharm Pharmacol. 1989;41(11):797-798.

43. Bendel S, Ruokonen E, Pölönen P, Uusaro A. Propofol causes more hypotension than etomidate in patients with severe aortic stenosis: a double-blind, randomized study comparing propofol and etomidate. Acta Anaesthesiol Scand. 2007;51(3):284-289.

44. Landoni G, Biondi-Zoccai GG, Zangrillo A, et al. Desflurane and sevoflurane in cardiac surgery: a meta-analysis of randomized clinical trials. J Cardiothorac Vasc Anesth. 2007;21(4):502-511.

45. Thwaites A, Edmends S, Smith I. Inhalation induction with sevoflurane: a double-blind comparison with propofol. Br J Anaesth. 1997;78(4):356-361.

46. Ebert TJ, Perez F, Uhrich TD, Deshur MA. Desflurane-mediated sympathetic activation occurs in humans despite preventing hypotension and baroreceptor unloading. Anesthesiology. 1998;88(5): 1227-1232.

47. Derwall M, Coburn M, Rex S, Hein M, Rossaint R, Fries M. Xenon: recent developments and future perspectives. Minerva Anestesiol. 2009;75(1-2):37-45.

48. Neukirchen M, Hipp J, Schaefer MS, et al. Cardiovascular stability and unchanged muscle sympathetic activity during xenon anaesthesia: role of norepinephrine uptake inhibition. Br J Anaesth. 2012;109(6): $887-896$.

49. Baumert JH, Hein M, Hecker KE, Satlow S, Neef P, Rossaint R. Xenon or propofol anaesthesia for patients at cardiovascular risk in non-cardiac surgery. Br J Anaesth. 2008;100(5):605-611.

50. Tarkkila PJ, Kaukinen S. Complications during spinal anesthesia: a prospective study. Reg Anesth. 1991;16(2):101-106. 
51. Carpenter RL, Caplan RA, Brown DL, Stephenson C, Wu R. Incidence and risk factors for side effects of spinal anesthesia. Anesthesiology. 1992;76(6):906-916.

52. Leo S, Sng BL, Lim Y, Sia AT. A randomized comparison of low doses of hyperbaric bupivacaine in combined spinal-epidural anesthesia for cesarean delivery. Anesth Analg. 2009;109(5):1600-1605.

53. Ben-David B, Frankel R, Arzumonov T, Marchevsky Y, Volpin G. Minidose bupivacaine-fentanyl spinal anesthesia for surgical repair of hip fracture in the aged. Anesthesiology. 2000;92(1):6-10.

54. Malinovsky JM, Renaud G, Le Corre P, et al. Intrathecal bupivacaine in humans: influence of volume and baricity of solutions. Anesthesiology. 1999;91(5):1260-1266.

55. Obasuyi BI, Fyneface-Ogan S, Mato CN. A comparison of the haemodynamic effects of lateral and sitting positions during induction of spinal anaesthesia for caesarean section. Int J Obstet Anesth. 2013;22(2):124-128.

56. Loubert C, Hallworth S, Fernando R, et al. Does the baricity of bupivacaine influence intrathecal spread in the prolonged sitting position before elective cesarean delivery? A prospective randomized controlled study. Anesth Analg. 2011;113(4):811-817.

57. Trentman TL, Fassett SL, Thomas JK, Noble BN, Renfree KJ, Hattrup SJ. More hypotension in patients taking antihypertensives preoperatively during shoulder surgery in the beach chair position. Can J Anaesth. 2011;58(11):993-1000.

58. Yokoyama M, Ueda W, Hirakawa M, Yamamoto H. Hemodynamic effect of the prone position during anesthesia. Acta Anaesthesiol Scand. 1991;35(8):741-744.

59. Joris JL, Noirot DP, Legrand MJ, Jacquet NJ, Lamy ML. Hemodynamic changes during laparoscopic cholecystectomy. Anesth Analg. 1993;76(5):1067-1071.

60. Popescu WM, Bell R, Duffy AJ, Katz KH, Perrino AC Jr. A pilot study of patients with clinically severe obesity undergoing laparoscopic surgery: evidence for impaired cardiac performance. $J$ Cardiothorac Vasc Anesth. 2011;25(6):943-949.

61. Lestar M, Gunnarsson L, Lagerstrand L, Wiklund P, OdebergWernerman S. Hemodynamic perturbations during robot-assisted laparoscopic radical prostatectomy in $45^{\circ}$ Trendelenburg position. Anesth Analg. 2011;113(5):1069-1075.

62. Girardis M, Milesi S, Donato S, et al. The hemodynamic and metabolic effects of tourniquet application during knee surgery. Anesth Analg. 2000;91(3):727-731.

63. Gelman S. The pathophysiology of aortic cross-clamping and unclamping. Anesthesiology. 1995;82(4):1026-1060.

64. Qvist J, Pontoppidan H, Wilson RS, Lowenstein E, Laver MB. Hemodynamic responses to mechanical ventilation with PEEP: the effect of hypervolemia. Anesthesiology. 1975;42(1):45-55.

65. Kyhl K, Ahtarovski KA, Iversen K, et al. The decrease of cardiac chamber volumes and output during positive-pressure ventilation. $\mathrm{Am}$ J Physiol Heart Circ Physiol. 2013;305(7):H1004-H1009.

66. Monnin M, Lonjaret L, Fourcade O, Geeraerts T. Réaction d'hypersensibilité immédiate au cisatracurium. Intérêt des tests cutanés [Immediate hypersensitivity to cisatracurium. Value of skin tests]. Ann Fr Anesth Reanim. 2012;31(10):824-825. French.

67. Eissa D, Carton EG, Buggy DJ. Anaesthetic management of patients with severe sepsis. Br J Anaesth. 2010;105(6):734-743.

68. Heck M, Kumle B, Boldt J, Lang J, Lehmann A, Saggau W. Electroencephalogram bispectral index predicts hemodynamic and arousal reactions during induction of anesthesia in patients undergoing cardiac surgery. J Cardiothorac Vasc Anesth. 2000;14(6): 693-697.

69. Sessler DI, Sigl JC, Kelley SD, et al. Hospital stay and mortality are increased in patients having a "triple low" of low blood pressure, low bispectral index, and low minimum alveolar concentration of volatile anesthesia. Anesthesiology. 2012;116(6):1195-1203.

70. Casati A, Fanelli G, Aldegheri G, et al. Frequency of hypotension during conventional or asymmetric hyperbaric spinal block. Reg Anesth Pain Med. 1999;24(3):214-219.
71. Casati A, Aldegheri G, Vinciguerra E, Marsan A, Fraschini G, Torri G. Randomized comparison between sevoflurane anaesthesia and unilateral spinal anaesthesia in elderly patients undergoing orthopaedic surgery. Eur J Anaesthesiol. 2003;20(8):640-646.

72. Minville V, Fourcade O, Grousset D, et al. Spinal anesthesia using single injection small-dose bupivacaine versus continuous catheter injection techniques for surgical repair of hip fracture in elderly patients. Anesth Analg. 2006;102(5):1559-1563.

73. Lonjaret L, Lairez O, Fourcade O, Minville V. Rachianesthésie continue et hypertension artérielle pulmonaire [Continuous spinal anesthesia and pulmonary arterial hypertension]. Ann Fr Anesth Reanim. 2012;31(10):810-812. French.

74. Biboulet P, Jourdan A, Van Haevre V, et al. Hemodynamic profile of target-controlled spinal anesthesia compared with 2 target-controlled general anesthesia techniques in elderly patients with cardiac comorbidities. Reg Anesth Pain Med. 2012;37(4):433-440.

75. Arzola C, Wieczorek PM. Efficacy of low-dose bupivacaine in spinal anaesthesia for Caesarean delivery: systematic review and meta-analysis. Br J Anaesth. 2011;107(3):308-318.

76. Dobrydnjov I, Axelsson K, Thörn SE, et al. Clonidine combined with small-dose bupivacaine during spinal anesthesia for inguinal herniorrhaphy: a randomized double-blinded study. Anesth Analg. 2003;96(5):1496-1503.

77. Colson P, Ryckwaert F, Coriat P. Renin angiotensin system antagonists and anesthesia. Anesth Analg. 1999;89(5):1143-1155.

78. Mebazaa A, Pitsis AA, Rudiger A, et al. Clinical review: practical recommendations on the management of perioperative heart failure in cardiac surgery. Crit Care. 2010;14(2):201.

79. Saravanan S, Kocarev M, Wilson RC, Watkins E, Columb MO, Lyons G. Equivalent dose of ephedrine and phenylephrine in the prevention of post-spinal hypotension in Caesarean section. Br J Anaesth. 2006;96(1):95-99.

80. Mercier FJ, Augè M, Hoffmann C, Fischer C, Le Gouez A. Maternal hypotension during spinal anesthesia for caesarean delivery. Minerva Anestesiol. 2013;79(1):62-73.

81. De Backer D, Biston P, Devriendt J, et al; SOAP II Investigators. Comparison of dopamine and norepinephrine in the treatment of shock. N Engl J Med. 2010;362(9):779-789.

82. Longrois D, Lejus C, Constant I, Bruyère M, Mertes PM. Traitement des réactions anaphylactiques survenant en cours d'anesthésie et en particulier du choc anaphylactique [Treatment of hypersensitivity reactions and anaphylactic shock occurring during anaesthesia]. Ann Fr Anesth Reanim. 2011;30(3):312-322. French.

83. Eyraud D, Brabant S, Nathalie D, et al. Treatment of intraoperative refractory hypotension with terlipressin in patients chronically treated with an antagonist of the renin-angiotensin system. Anesth Analg. 1999;88(5):980-984.

84. Boccara G, Ouattara A, Godet G, et al. Terlipressin versus norepinephrine to correct refractory arterial hypotension after general anesthesia in patients chronically treated with renin-angiotensin system inhibitors. Anesthesiology. 2003;98(6):1338-1344.

85. Helfman SM, Gold MI, DeLisser EA, Herrington CA. Which drug prevents tachycardia and hypertension associated with tracheal intubation: lidocaine, fentanyl, or esmolol? Anesth Analg. 1991;72(4): 482-486.

86. Pigott DW, Nagle C, Allman K, Westaby S, Evans RD. Effect of omitting regular ACE inhibitor medication before cardiac surgery on haemodynamic variables and vasoactive drug requirements. $\mathrm{Br} J$ Anaesth. 1999;83(5):715-720.

87. Vuylsteke A, Vincent JL, de La Garanderie DP, et al; Euro-STAT Investigators. Characteristics, practice patterns, and outcomes in patients with acute hypertension: European registry for Studying the Treatment of Acute hyperTension (Euro-STAT). Crit Care. 2011;15(6):R271.

88. Yu SK, Tait G, Karkouti K, Wijeysundera D, McCluskey S, Beattie WS. The safety of perioperative esmolol: a systematic review and meta-analysis of randomized controlled trials. Anesth Analg. 2011;112(2):267-281. 
89. Aronson S, Dyke CM, Stierer KA, et al. The ECLIPSE trials: comparative studies of clevidipine to nitroglycerin, sodium nitroprusside, and nicardipine for acute hypertension treatment in cardiac surgery patients. Anesth Analg. 2008;107(4):1110-1121.

90. Kaplan JA. Clinical considerations for the use of intravenous nicardipine in the treatment of postoperative hypertension. Am Heart J. 1990; 119(2 Pt 2):443-446.

91. Lien SF, Bisognano JD. Perioperative hypertension: defining at-risk patients and their management. Curr Hypertens Rep. 2012;14(5): $432-441$.

92. Wijeysundera DN, Bender JS, Beattie WS. Alpha-2 adrenergic agonists for the prevention of cardiac complications among patients undergoing surgery. Cochrane Database Syst Rev. 2009;7(4):CD004126.
93. Biccard BM, Goga S, de Beurs J. Dexmedetomidine and cardiac protection for non-cardiac surgery: a meta-analysis of randomised controlled trials. Anaesthesia. 2008;63(1):4-14

94. Dooley M, Goa KL. Urapidil. A reappraisal of its use in the management of hypertension. Drugs. 1998;56(5):929-955.

95. van der Stroom JG, van Wezel HB, Langemeijer JJ, et al. A randomized multicenter double-blind comparison of urapidil and ketanserin in hypertensive patients after coronary artery surgery. $J$ Cardiothorac Vasc Anesth. 1997;11(6):729-736.

\section{Publish your work in this journal}

Integrated Blood Pressure Control is an international, peer-reviewed open-access journal focusing on the integrated approach to managing hypertension and risk reduction. Treating the patient and comorbidities together with diet and lifestyle modification and optimizing healthcare resources through a multidisciplinary team approach constitute key features of the journal. This journal is indexed on American Chemical Society's Chemical Abstracts Service (CAS). The manuscript management system is completely online and includes a very quick and fair peerreview system, which is all easy to use. Visit http://www.dovepress.com/ testimonials.php to read real quotes from published authors.

\footnotetext{
Submit your manuscript here: http://www.dovepress.com/integrated-blood-pressure-control-journal
} 